\title{
Assessment of Undergraduate Students in Use of Hypermedia Education on Peripheral Venous Punch
}

\author{
Natasha Marques Frota, Lívia Moreira Barros, Francisco Gilberto Fernandes Pereira, \\ Máguida Gomes da Silva, Jennara Candido do Nascimento, Monaliza Ribeiro Mariano, \\ Joselany Áfio Caetano
}

Department of Nursing, Federal University of Ceará, Fortaleza, Brazil

Email: natashafrota @hotmail.com

Received 10 March 2015; accepted 2 April 2015; published 3 April 2015

Copyright (C) 2015 by authors and Scientific Research Publishing Inc. This work is licensed under the Creative Commons Attribution International License (CC BY). http://creativecommons.org/licenses/by/4.0/

\section{(c) (i) Open Access}

\begin{abstract}
This is a qualitative study that aims to describe the opinion of nursing students on the use of an educational hypermedia on Peripheral Venipuncture. We interviewed 16 nursing students of a private university on second semester of 2014. The interviews allowed the identification of units of meaning and categorization by content analysis and led to four categories: influence of hypermedia on learning, educational technology as support to teaching classroom, contribution of hypermedia for professional practice and access difficulties. Hypermedia showed positive results as most scholars reported that the material helped in learning and generated autonomy and interactivity in the moment of studying. However some reported difficulties in access hypermedia related mainly to the server used. So hypermedia proved to be a valuable tool to use, since it favored the learning and aroused the interest and curiosity of students.
\end{abstract}

\section{Keywords}

Nursing, Internet, Educational Technology, Educational Measurement, Catherization Peripheral

\section{Introduction}

The use of Information and Communication Technologies (ICTs) in educational field has brought significant changes in the interactions and interactivity in teaching and learning. Due to this factor, there was a large increase in the number of courses, both in the classroom mode and in the distance, being mediated by Virtual Learning Environments (VLE) [1]. 
The VLE can be defined as a computer system available on the internet that is destined to support activities mediated by information and communication technologies and allows the process of teaching and learning through pedagogical mediation between students and teacher. It is capable of integrating multiple media, languages and resources and presents information in an organized way, besides it can also broaden the interactions between individuals and objects of knowledge providing the socialization experiences and productions [2].

Parallel to this development, teaching and research in nursing have sought to fit into advances in education technology. New teaching and learning strategies are being inserted in nursing, including the methodologies that provide the student greater autonomy in learning. Among the various educational resources we highlight the educational hypermedia, which allows the user to receive information by computer and interpret them, allowing the construction process of knowledge in a pleasant, efficient and interactive way [3].

However, despite technological advances in nursing, there are still some procedures such as Peripheral Venipuncture (PV), that cause anxiety and insecurity in students, which warns the need to develop new teaching strategies that give allowance for students to perform their practical activities with success and security, given that the PV is a procedure routinely performed during the care of the nursing team.

Facing this context, the use of hypermedia mediated by VLE provides a complement in the training of student in order to perform certain procedures safely, because it brings the student closer to reality.

Given these considerations, it is appropriate to carry out this study due to the increased use of information technology in nursing education, approaching the student to the practical reality of their area. It is noteworthy that the results of this study can contribute to the improvement of existing tools and technologies in the field of nursing, considering that the students' opinions about the use of a hypermedia and the difficulties experienced in VLEs allow this gaps adjustment in education as well as the assessment of teaching through education distance learning (DL).

With this the objective of the study was to describe the opinion of nursing students on the use of an educational hypermedia on Peripheral Venipuncture.

\section{Methods}

\subsection{Study Design and Participants}

This is a qualitative study developed during the second semester of 2014, at Estacio University Center of Ceará, Brazil, together with the students of undergraduate nursing attending penultimate school year.

This study used an educational hypermedia in the form of a DL course for nursing students of the Adult Health course as an additional and voluntary activity with a workload of 16 hours/week. Hypermedia is available in Solar Platform, available on http://solarpresencial.virtual.ufc.br/ address.

\subsection{Measures}

In order the student to access to the course, it was necessary to register with VLE with username and password available to perform the login. The access to the room was possible after the approval by the tutor/teacher, from the registration application of user.

On the homepage of hypermedia students had access to classes, organized into six modules, which are divided into topics: Module 1: Introduction to peripheral venipuncture; Module 2: Anatomy of the venous network; Module 3: peripheral venipuncture procedure; Module 4: local and systemic complications of PVP; Module 5: Peripheral venipuncture in special patients; and Module 6: Actions of not conformity of PVP.

During the classes there are different tools such as videos, photos, hypertext, hyperlinks and exercises, that allow interaction between students. This diversity of tools also allows hypermedia to become attractive as it is being used by students.

Thus, in order to identify the views of students on the use of hypermedia on PVP, inclusion criteria were established: to be regularly enrolled in adult health discipline, to have some basic computer knowledge, to use the virtual learning environment and to access all classes available in hypermedia. Exclusion criteria were: students who conducted courses on PVP previously and who have not completed the evaluation of hypermedia in a timely manner.

There were 35 potential participants for the study in this institution. After the interview with 16 of the 35 students, we observed the absence of new information and we made sure that there was data saturation, leading us 
to complete the data collection. Therewith, participated in the study 16 nursing students, being this number conditioned to the criteria of findings saturation, which occurs when the information becomes repeated or the addition of new data is minimal to submit to the analysis procedures [4].

Data collection was conducted in a private room in the university, as the participants' availability and in alternative schedules classes in order to not interrupt the participation of students in their school activities. To achieve the objective of the study we used semi-structured interviews as a data collection technique in which it was addressed thematic issues such as the use of educational technologies for teaching nursing, the access to digital learning materials as well as the main limitations found in this type of education mode. The interviews were recorded according to the authorization of the students and lasted between 20 - 60 minutes and being fully transcribed.

The analysis of the empirical data was performed by three researchers and occurred in the following steps: pre-analysis; material exploration; treatment of findings and interpretation according to guidelines for content analysis [4].

The ethical aspects of research involving human beings were respected, according to the principles of the Declaration of Helsinki. Participants received information about the nature; objectives and risks related to the study and voluntarily signed the Free and Clarified Consent Term. To preserve anonymity, the students were identified by the word student followed by a number representing the order of entry into the study.

\section{Results}

The study included 16 nursing students, predominantly female (14 women and two men) and in the age group of 22 - 26 years. All reported having easy access to Internet at home, at the university through the wireless network, the computer room, library and research groups.

In addition, all students also had access to the Internet via cell phone and reported that this served as support in performing their graduation activities, as they prefer the Internet instead of manuals and books for clarifying doubts and study for content of course subjects.

From this scenario, the data analysis process allowed the identification of four categories: influence of hypermedia in learning; educational technology as a support to classroom teaching; relation of hypermedia with professional practice; and access difficulties.

\subsection{Influence of Hypermedia on Learning}

The exchange of information between academics through existing tools in hypermedia as forums and chats allows interactivity between students and the tutor as the sharing of questions and feedback from the knowledge gained. You can see this influence through the following lines:

The hypermedia material presents issues that we do not always see in the classroom... (Student 15)

The review of the venous network was very well addressed... (Student 9)

The knowledge about the different technical possibilities, anatomy of vascular network and the possible

complications of an incorrect venipuncture... (Student 11)

Better understanding of the veins and their locations, review the technical and theory... (Student 6)

In this sense, hypermedia was favorable to the acquisition of knowledge since the study subjects stated that the use of VLE provided an enhancement of knowledge on PVP as the anatomy of the venous network, the materials used and the nursing care, thereby, allowing the association between theory and practice.

\subsection{Educational Technology as Support to Classroom Teaching}

The use of technology in education can serve as a basis for training that goes beyond the classroom, enabling the student to choose the ideal time for learning. Moreover, in hypermedia, the student has access to the various interactive media that facilitate the acquisition of knowledge due to the numerous possibilities of learning. The statements below depict this interaction:

What most caught my attention was the interactivity and flexibility of working hours... (Student 2)

Some information I had never heard either in laboratory classes or in practical classes... (Student 7) 
Hypermedia can be seen as a flexible and pleasant environment for studies, which is able to address questions and promote new knowledge, thus contributing as a support tool to contents given in class.

\subsection{Contribution of Hypermedia in Professional Practice}

The practice of peripheral venous puncture is one of the basics responsibilities of nursing team, which requires professional technical and scientific knowledge on the subject. Can be seen through the speeches:

I found it very important for nursing, in addition to the way it was presented to us... (Student 4)

The university has been working with subjects in the online mode, but the subject matter discussed in hypermedia was not part of this context... (Student 15)

I found the content of extreme importance to professional practice and I intend to enroll in other distance courses... (Student 14)

Hypermedia serves to assist the nursing student in the performance of their activities in compliance with the patients in early hospital practice, because it facilitates the teaching-learning process of students on memorizing the sequence of technique, allowing access to learning materials and interactive at the desired time and reducing doubts arising from the different embodiments of the same procedure. In addition, over professional life hypermedia is a continuous learning tool, recycling the knowledge of the technique, thereby promoting continuing professional education.

\subsection{Access Difficulties of Virtual Environment}

In this study, some participants reported difficulties in accessing hypermedia related mainly to the server used. Thus, we see the need for guidance to academics to facilitating access to information, to allow the use of more efficient tool by users.

I did not know that the choice of browser influenced the navigation system... (Student 2)

At times the system did not recognize my password... (Student 5)

I felt difficulty accessing some videos, due to the chosen server... (Student 9)

After registration I had to wait for the release of the course by the tutor, but I would like to start using hypermedia as soon as possible... (Student 11)

Therefore, it is necessary to take special care to foresee the user or group difficulties on the environment that will be used, for easy navigation, accessibility and functionality becomes an effective and comprehensive learning minimizing the possible obstacles for the use the VLE.

\section{Discussion}

The introduction of new technologies, including ICTs, has revolutionized the traditional style of education and opened new possibilities in the form of online education, requiring the development of more suitable teaching strategies and learning for distance education [5].

With the advances of globalization, ICTs require teachers to rethink teaching methods to be used during the process of teaching and learning, making new strategies that are being developed to meet the expectations of a new generation of students with extensive experience in the use of technologies [6]. In order to face this challenge requires new and creative approaches to improve efficiency and effectiveness in the learning process in nursing education [7].

Among the different resources available for use in nursing education, technology is environment to improve the practice of teaching and nursing care, requiring critical analysis of the context in which this technology will be inserted, expressing the educational intention that permeates the its use. Also, another relevant point is the encouragement of teachers to adopt these technological innovations in order to enhance learning [8].

However, to occur a positive effect on student learning the teacher should choose an educational technology that meets the goals of education and the expectations of both teacher and students, besides providing instructional tasks and meeting the needs of students [9].

In several European countries, there is already a government concern to reform the education system with the implementation of more effective teaching practices and learning and the use of modern educational technolo- 
gies [9]. For health professionals in training, ICT is commonly used in the educational process and, among the main advantages of ICTs, there is the possibility of learning occur anywhere and anytime. As important pedagogical advantages, we are able to adapt to the learning style and rhythm of each student and the possibility of repeating the content that was taught [10].

The expectations of students in relation to inclusion of learning educational technologies are the possibility of access to information beyond the university. The information is aimed at the practical application, with the provision of video, photos, links and hypertext, detailing the implementation of the procedure.

Distance learning has become an existing tool at all levels of the education system due to advantages such as flexibility, ease of access, modular character, quality of virtual environment and cost-effectiveness [9]. In hypermedia environment all information can be accessed via hyperlinks in the form of text, images, video or sound, and students can explore the environment in their way [10]. The use of audio-visual aids can attract students to navigate the virtual environmental and motivate significantly the learning of these students with a positive impact on learning outcomes [6].

The use of hypermedia allowed complementing the theoretical content provided in classroom, for it made available to students illustrative additional materials about PVP, with complementary videos and activities. This allowed the junction between knowledge and teacher's experience in academia and the use of a rich virtual environment in tools for deepening techniques for performing the procedure. Quick access to a vast amount of information available is seen as beneficial because it allows students a multifaceted mental representation of the content in question [11].

The use of effective learning strategies is propitious to the development of metacognitive capacity. Metacognition is an active process of knowing, being the integrating element between knowledge and cognition. Students of undergraduate nursing are in the development phase of metacognitive abilities for effective performance during practice. Among these qualities, we have to reflect on their activities for making decisions, selfawareness of strengths and weaknesses, identification of strategies for learning and self-monitoring of learned knowledge [5].

The virtual environment aroused the interest of students because of the ease of access to knowledge and availability of the material in the virtual environment and facilitated communication with the tutor of hypermedia. The interaction with other students and the tutor was cited by students as the use of hypermedia advantage. One of the potential use of VLEs is interactivity as a possibility for reflection and exchange in the construction of knowledge to be used by the mediator [12].

Nursing students who had the experience of using hypermedia for teaching revealed that found the teaching method was easiest to acquire knowledge related to the content in virtual environment [13], getting closer to your learning objectives [5].

The classroom environment can be incompatible with the preferred learning style of students, making it difficult to process information and learning, resulting in stress and frustration [14]. By using virtual learning environments for educational practices, teachers can increase the amount of time available for student learning content, making it active in the learning process. In addition, tools such as chats and forums also allow for interaction among students in which they can learn and exchange mutually doubts [7].

The results of use of hypermedia show that these virtual environments can increase the interest and motivation of students, it can also adapt to preferences and cognitive needs, it allow the processing of active and constructive information and stimulate the acquisition of self-regulatory skills, as well to allow the provision of additional information and enable chats and forums for questions. However, usability issues as disorientation, distraction and cognitive overload can also occur [8].

In a survey carried out with nursing students it was observed that they considered the video of hypermedia used in the study relevant to clinical practice, demonstrating that the use of such teaching resource encourages learning and has a significant impact on professional career. Hypermedia provides faster access to information environment in various formats and opportunity of freedom access to knowledge [15].

It is clear that hypermedia allows students the control over their learning in which they can select the modules and choose the sequence of presentation of information according to your goals and your time and rhythm [16]. It is believed that the VLEs can increase potential learning, can increase learner's responsibility for the process of teaching and learning, greater collaboration of students in the educational process and better quality learning [5].

Currently, the focus of teachers in educational process is the identity of the student. More and more emphasis 
is being placed on the need for development and improvement of creative and intellectual abilities of individual students involved in the preparation and strengthening of skills in practice [10]. The use of an attractive instructional design may (re)direct the focus of student for cognitive processes that are necessary for learning and memorizing the teaching construction schemes [9].

The findings of the study indicate the need to guide students on the properties of the software used and to identify the difficulties before the learning process begin in order to prevent possible viewing trouble and digital material saving on your computer [7]. Information obtained from the perception of the students are very valuable to solve aspects that are not covered and the execution of changes, according to students' needs and learning goals.

So to be successful in learning, there are some requirements as: students must have prior knowledge of the content and of the skills involved in training; the inclinable teaching in educational technology represents a more advanced lesson in a course or a more advanced course in the curriculum; students must have good metacognitive skills and the course cannot present a highly complex content [10].

It is inferred, therefore, that today's students represent the generation of "digital natives" who prefer that their learning experience is integrated with digital media. Thus, it is noticed that the computer certainly earned its place in education for the new generation of students, as the use of educational technologies to improve learning. This is especially true for nursing education due to the requirement of prudent decision-making of nurses in clinical settings [10].

To maximize the effects of effective use of educational technology in learning, teachers should consider before implementation, the results of expected learning, learning needs and individual preferences of the students, the implementation of logistics and technical support. With careful planning, experience in teaching in a virtual environment can promote active learning of students [17].

It also stands out that for the full success of the tool, VLE should provide adequate access and rely on educators and motivated and updated tutors. However, the student's access is fundamental and it is essential to be participatory and active, access the contents, materials look beyond the proposed texts and contribute reflections for discussion [18].

\section{Limitations and Recommendations for Futures Studies}

This study is limited by the samplesize was small for the collection of data, requiring realizer future studies with others tudents in other higher education institutions to analyze the importance of educational hyper media on peripheral venipuncture.

\section{Conclusion and Clinical Implications}

Hypermedia was presented as a positive tool to be used in the teaching-learning process related to the theme peripheral venipuncture. The construction and use of technology resources have been shown increasingly effective, being its application in teaching or in practice something increasingly explored in nursing and especially in teaching environment.

With this study, we saw the need to develop similar hypermedia, addressing the various nursing techniques with free and easy access to all academic professionals to provide continuing education of these.

\section{Conflict of Interest}

No conflict declared.

\section{Acknowledgements}

We would like to thank all participants in the study.

\section{References}

[1] Fruet, F.S.O. and Bastos, F.P.B. (2010) Interação media da por computador: Hipermídia educacion alnasatividades de estudo a distância. Conjectura, 15, 81-98.

[2] Grossi, M.G.R., Moraes, A.L. and Breseia, A.T. (2013) Interatividade em ambientes virtuais de aprendizagem no pro- 
cesso de ensino e aprendizagem na educação a distância. Arquivo Brasileiro de Educação, 1, 75-92. http://periodicos.pucminas.br/index.php/arquivobrasileiroeducacao/article/view/5683/5543

[3] Alavarce, D.C. and Pierin, A.M.G. (2011) Development of Educational Hypermedia to Teach an Arterial Blood Pressure Measurement Procedure. Revista da Escola de Enfermagem da USP, 45, 939-944. http://dx.doi.org/10.1590/S0080-62342011000400021

[4] Bardin, L. (2010) Análise de conteúdo. Setenta, 41.

[5] Li-Ling, H. and Suh-Ing, H. (2014) Factors Affecting Metacognition of Undergraduate Nursing Students in a Blended Learning Environment. International Journal of Nursing Practice, 20, 233-241.

[6] Commendador, K. and Chi, R. (2013) Comparative Analysis of Nursing Students' Perspectives toward Avatar Learning Modality: Gain Pre-Clinical Experience via Self-Paced Cognitive Tool. Journal of Interactive Learning Research, 24, 151-166. http://www.editlib.org/p/40443/

[7] Posey, L. (2013) Best Practices in Blended Learning: Snapshots from a Hybrid Bachelor of Science in Nursing (BSN) Program. In: Jan Herrington, et al., Eds., Proceedings of World Conference on Educational Media and Technology 2013, Association for the Advancement of Computing in Education (AACE), 350-355. http://www.editlib.org/p/111979/

[8] Hariri, A. and Roberts, P. (2015). Adoption of Innovation within Universities: Proposing and Testing an Initial Model. Creative Education, 6, 186-203. http://dx.doi.org/10.4236/ce.2015.62017

[9] Smyrnova-Trybulska, E., Kommers, P. and Simmerling, M. (2014) Special Issue on Competences and Skills for Teaching Blended Learning. International Journal of Continuing Engineering Education and Life-Long Learning, 24, 213-218. http://doc.utwente.nl/92269/1/f472586101211193.pdf

[10] Te Pas, E., Waard, M.W.-D., Blok, B.S., Pouw, H. and Van Dijk, N. (2014) Didactic and Technical Considerations When Developing E-Learning and CME. Education and Information Technologies. http://link.springer.com/article/10.1007/s10639-014-9364-2/fulltext.html

[11] Scheiter, K., Gerjets P. and Heise, E. (2014) Distraction during Learning with Hypermedia: Difficult Tasks Help to Keep Task Goals on Track. Frontiers in Psychology, 5, 268. http://journal.frontiersin.org/article/10.3389/fpsyg.2014.00268/full

[12] Tétreault, M.A. (2015) Leaving Home? Global Education Strategies. Creative Education, 6, 115-126. http://dx.doi.org/10.4236/ce.2015.62010

[13] Ireland, J., Sheelagh, M., Johnson, N. and Adams, D. (2009) Blended Learning in Education: Effects on Knowledge and Attitude. British Journal of Nursing, 18, 124-130. http://dx.doi.org/10.12968/bjon.2009.18.2.37868

[14] Colace, F., De Santo, M. and Greco, L. (2014) E-Learning and Personalized Learning Path: A Proposal Based on the Adaptive Educational Hypermedia System. International Journal of Emerging Technologies in Learning, 9, 9-16. http://online-journals.org/index.php/i-jet/article/view/3211

[15] Cardoso, A.F., Moreli, L., Braga, F.T.M.M., Vasques, C.I., Santos, C.B. and Carvalho, E.C. (2012) Effect of a Video on Developing Skills in Undergraduate Nursing Students for the Management of Totally Implantable Central Venous Access Ports. Nurse Education Today, 32, 709-713. http://www.ncbi.nlm.nih.gov/pubmed/22036273

[16] Scheiter, K. and Gerjets, P. (2007) Learner Control in Hypermedia Environments. Educational Psychology Review, 19, 285-307. http://rolandhubscher.org/courses/hf765/readings/scheiter2007.pdf

[17] Bulu, S.R. and Pedersen, S. (2012) Supporting Problem-Solving Performance in a Hypermedia Learning Environment: The Role of Students’ Prior Knowledge and Metacognitive Skills. Computers in Human Behavior, 28, 1162-1169. http://www.sciencedirect.com/science/article/pii/S0747563212000283

[18] Frota, N.M., Barros, L.M., Araújo, T.M., Caldini, L.N., Nascimento, J.C. and Caetano, J.A. (2013) Construction of an Educational Technology for Teaching about Nursing on Peripheral Venipuncture. Revista gaucha Enfermagem, 34, 2936. http://seer.ufrgs.br/index.php/RevistaGauchadeEnfermagem/article/view/33258/26035 